Canadian

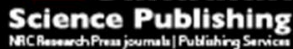

Canadian Geotechnical Journal Revue canadienne de géotechnique

\title{
A new approach to improve soil-water characteristic curve to reduce variation in estimation of unsaturated permeability function
}

\begin{tabular}{|r|l|}
\hline Journal: & Canadian Geotechnical Journal \\
\hline Manuscript ID & cgj-2015-0199.R1 \\
\hline Manuscript Type: & Note \\
\hline Date Submitted by the Author: & $09-$ Sep-2015 \\
\hline Complete List of Authors: & $\begin{array}{l}\text { Rahimi, Arezoo; Nanyang Technological University, Civil and Environmental } \\
\text { Engineering } \\
\text { Rahardjo, Harianto; Nanyang Technological University, }\end{array}$ \\
\hline Keyword: & $\begin{array}{l}\text { Grain-size distribution, soil-water characteristic curve, unsaturated } \\
\text { permeability function, estimation, direct measurement }\end{array}$ \\
\hline
\end{tabular}

\section{SCHOLARONE \\ Manuscripts}


Title: A new approach to improve soil-water characteristic curve to reduce variation in estimation of unsaturated permeability function

Authors: Arezoo Rahimi; Harianto Rahardjo

\begin{abstract}
:
Unsaturated permeability function is often estimated from soil-water characteristic curve (SWCC) of a soil. A complete SWCC measurement can improve the estimation of unsaturated permeability function. In most laboratories, SWCC can be measured up to 100 $\mathrm{kPa}$ suction using a Tempe cell. However, the complete measurement of SWCC is an expensive and time-consuming task. Therefore, this paper presents a new approach to estimate SWCC data points beyond $100 \mathrm{kPa}$ suction in order to complement the measured SWCC up to $100 \mathrm{kPa}$ suction. The new SWCC is then used to estimate the unsaturated permeability function. The proposed approach uses knowledge of grain-size distribution curve and the measured SWCC data at $100 \mathrm{kPa}$ suction to estimate the SWCC data points beyond $100 \mathrm{kPa}$ suction. In order to verify the proposed procedure, SWCC tests were conducted over a wide range of suctions for coarse kaolin and a triaxial permeameter system was used to directly measure the unsaturated permeability of the coarse kaolin. The proposed procedure is found to reduce the variation between unsaturated permeability functions estimated by various estimation models.
\end{abstract}

\title{
Key words:
}

Grain-size distribution, soil-water characteristic curve, unsaturated permeability function, estimation, direct measurement 


\section{Introduction:}

Unsaturated permeability function is often estimated from soil-water characteristic curve (SWCC) of a soil by various estimation models proposed up to date. The estimation procedure consists of best-fitting the measured SWCC data by a best-fit SWCC equation and integration of the best-fitted SWCC by means of an integration method (i.e., relative permeability equation). The variation between the estimated unsaturated permeability functions using different estimation models was investigated by Rahimi et al. (2015, 2014). It was shown that the measured SWCC data ranges were the most important parameter which caused the variation between all the estimated unsaturated permeability functions obtained from the various models. It was also shown that the complete measured SWCC could eliminate the variation between all the estimated unsaturated permeability functions. Kunze et al. (1968) has reported that a complete SWCC measurement may improve the estimation of unsaturated permeability function. The complete measurement of SWCC may not be practical due to the time and equipments required. However, in most laboratories, SWCC can be measured up to $100 \mathrm{kPa}$ using a Tempe cell. Therefore, the objective of this study is to propose a new approach for estimating SWCC data points beyond $100 \mathrm{kPa}$ to complement the measured SWCC up to the $100 \mathrm{kPa}$ suction. The new SWCC is then used to estimate the unsaturated permeability function. The proposed approach uses the knowledge of grain-size distribution curve and the measured SWCC data at $100 \mathrm{kPa}$ suction to estimate the SWCC data points beyond $100 \mathrm{kPa}$ suction value.

A term Pedo-Transfer Function (PTF) has been used to describe SWCC estimation functions that relate basic soil properties to yield a soil property function (Bouma 1989; Wösten et al. 2001). The estimation algorithms for SWCC have been classified into four major approaches by Johari et al. (2006): 1) in the first approach, the water contents at different matric suction 
values are estimated statistically (Gupta and Larson 1979; Saxton et al. 1986). The water contents and soil properties are then correlated at a selected suction value using regression analysis followed by a curve-fitting procedure, 2) in the second approach, regression analysis is used to correlate soil properties with the fitting parameters of an analytical equation representing the SWCC (Ahuja et al. 1985; Zapata 1999; Chin et al. 2010), 3) in the third approach, the SWCC is estimated using a physics-based conceptual model (Arya and Paris 1981; Kovács 1981; Smettem and Gregory 1996; Fredlund 2002) that involves the conversion of a grain size distribution into a pore-size distribution, 4) in the fourth approach, artificial intelligence methods, such as neural networks, genetic programming and other machine learning methods (Pachepsky et al. 1996; Johari et al. 2006; Garg et al. 2014) that involve training the model with an existing database and using the model to estimate the SWCC of other soils, are used.

It should be noted that, although PTF can be used to estimate the SWCC of a soil, it still has limitations due to the underlying assumptions used in the method. Therefore, the estimated SWCC may not be the same as the measured one. The proposed procedure is similar to the third approach (a physics-based conceptual model) which involves the conversion of the grain size distribution into a pore-size distribution. However, the proposed procedure is independent of the soil database and is applicable for suctions beyond $100 \mathrm{kPa}$.

\section{Methodology}

A grain-size distribution curve (GSD) of a typical soil is shown in Figure 1.

A random assembly of soil grains creates a specific pore-structure for any soil and the SWCC of a soil is greatly dependent on its pore-structure (Rahardjo et al. 2012; Sillers et al. 2001; Fredlund and Xing 1994). One of the possible assemblies of a soil with an idealized dense 
packing condition (Jaafar and Likos 2011) is shown in Figure 1 and the pore space created by the soil grains can be seen in the figure. The radius of the pore can be computed using knowledge of the grain sizes creating that pore. The pore-structure of a soil is usually considered as a series of capillary tubes with various sizes (Fredlund and Rahardjo 1993). The pore size is related to the height of each capillary tube using the Young-Laplace equation which is equivalent to a suction value (Fredlund and Rahardjo 1993). It is assumed that the pore will be emptied once the suction applied to the soil increases beyond its equivalent suction. Once the suction applied to the soil has increased beyond the suction equivalent to the largest pore size, the soil starts to desaturate.

In a soil with an idealized dense packing condition, for any grain size available in the grain size distribution curve, the assembly of three soil grains of the same size (see Figure 2) would create the largest possible pore size for this grain size and the smaller grain sizes. It should be noted that the assembly of a particular grain size with its smaller grains would result in smaller pore sizes. Therefore, the largest pore that is created by the assembly of three grains of the same size would be emptied at its equivalent suction as computed by the YoungLaplace equation. The smaller pores created by the assembly of that grain size with its smaller grain sizes would remain saturated at that suction. This means that, for any grain size, the percent finer, $\mathrm{PF}(\%)$, could be related to the water content at the equivalent suction of that grain size. In other words, the water content for that grain size reflects that the smaller pores remain fully saturated at the equivalent suction. If the soil grains are assumed to have a spherical shape with an idealized dense packing condition similar to that shown in Figure 2, the radius of the pore can be computed according to Equation 1, which is known as Descartes' theorem. 
$\frac{1}{R_{P}}=\frac{6+4 \sqrt{3}}{D_{g}}$

where $D_{g}$ is diameter of the grain and $R_{P}$ is radius of the pore created by three grains of the same size

The capillary height of the corresponding pore can be expressed in terms of the radius of that pore according to Equation 2 known as the Young-Laplace equation as follows:

$h_{c}=\frac{2 T_{s}}{\rho_{w} g R_{P}}$

where $h_{c}$ the capillary height $(\mathrm{m}), T_{s}$ is the surface tension $(\mathrm{N} / \mathrm{m}), \rho_{w}$ is the water density $\left(\mathrm{kg} / \mathrm{m}^{3}\right), g$ is the gravitational acceleration $\left(\mathrm{m} / \mathrm{s}^{2}\right)$ and $R_{P}$ is the radius of the pore $(\mathrm{m})$. The equivalent suction $(\psi)$, corresponding to each available grain diameter in the grain-size distribution curve of the soil can be computed according to Equation 3, which is obtained by substituting Equation 1 into Equation 2.

$\psi=(12+8 \sqrt{3}) \frac{T_{s}}{\rho_{w} g D_{g}}$

where $\psi$ is the soil suction, (m). By using Equation 3, the $\mathrm{x}$-axis of the grain size distribution curve (i.e., diameter) can be converted to equivalent suction $(\psi)$.

The percent finer, PF (\%), of that grain size could represent the percentage of smaller pores corresponding to that grain size. Therefore, the water content at any grain size can be computed according to Equation 4.

$w c=\frac{P F(\%) \times w c_{S a t}}{100}$ 
where $w c$ is the water content of the soil for any computed suction from Equation 3 and $w c_{\text {Sat }}$ is the saturated water content of the soil. Therefore, the SWCC data point beyond suction of $100 \mathrm{kPa}$ can be estimated using the actual measurement of SWCC at $100 \mathrm{kPa}$ and the GSD by the following step by step procedure:

1- The diameter corresponding to a suction of $100 \mathrm{kPa}$ is computed according to Equation 3 and is called $\mathrm{D}_{(100)}$

2- The percent finer (PF), corresponding to $D_{(100)}$ is determined from the GSD curve and multiplied by the saturated water content of the soil as a first estimation of water content, $\mathrm{wc}_{(100)}$, at $100 \mathrm{kPa}$

3- The first estimate of water content at $100 \mathrm{kPa}, \mathrm{wc}_{(100)}$, is scaled to the measured water content of the soil at $100 \mathrm{kPa}, \mathrm{wc}_{(\mathrm{m})}$, and the scaled factor is equal to $S_{f}=\frac{w c_{(100)}}{w c_{(m)}}$

4- The equivalent suction, $\psi_{(\mathrm{Xn})}$, of the available grain diameters, $\mathrm{D}_{(\mathrm{Xn})}$, smaller than $\mathrm{D}_{(100)}$ is computed according to Equation 3

5- The percent finer, PF, corresponding to $\mathrm{D}_{(\mathrm{Xn})}$ smaller than $\mathrm{D}_{(100)}$ is multiplied by the saturated water content of the soil as a first estimation of water content, $\mathrm{wc}_{(\mathrm{Xn})}$, at the computed suctions, $\psi_{(\mathrm{Xn})}$

6- The first estimation of water content, $\mathrm{wc}_{(\mathrm{Xn})}$, at the computed suctions, $\psi_{(\mathrm{Xn})}$, is scaled by dividing it by the scaled factor, $S_{f}$

Figure 3 shows a schematic diagram of the proposed procedure.

\section{Evaluation of the proposed method}

The proposed method for estimating the SWCC data points in a higher suction range was evaluated using the soil database from the SoilVision (2006) database. SoilVision (2006) is a 
large soil database consisting of over 6000 soils that includes details of the grain size distribution, texture, bulk density, porosity, specific gravity, saturated volumetric water content, SWCC and saturated and unsaturated coefficients of permeability. As described earlier, knowledge of the grain size distribution (GSD) and soil-water characteristic curve (SWCC) are required for the estimation procedure. There are 879 soils in the SoilVision database that contain both SWCC and grain size distribution data. However, only 145 of these soils fulfil the following criteria for selection to be used in this study.

1- The SWCC measurements must be available from saturations to at least one suction point beyond $100 \mathrm{kPa}$.

2- The SWCC measurements must be available for suctions around $100 \mathrm{kPa}$ (i.e., 90-110 $\mathrm{kPa})$.

3- The GSD must be available for grain diameters $\left(\mathrm{D}_{(\mathrm{Xn})}\right)$ equivalent to $\psi(\mathrm{Xn})$ beyond $100 \mathrm{kPa}$.

From the 145 soils in the SoilVision database which met the above criteria, forty (40) soils as shown in Table 1 were then randomly selected for use in the evaluation of the proposed method. The proposed method was applied to the selected soil database.

The measured SWCC data points versus the estimated SWCC data points are shown in Figure 4. The variability of the estimated SWCC data points versus the measured SWCC data points was computed by calculating the coefficient of determination, $\mathrm{R}^{2}$, according to Equation 5 .

$R^{2}=1-\frac{S S E}{S S T}$

where $S S T=S S R+S S E, S S R=\sum_{i=1}^{X}\left(\hat{\theta}_{w i}-\bar{\theta}_{w i}\right)=0, S S E=\sum_{i=1}^{X}\left(\theta_{w i}-\hat{\theta}_{w i}\right)=0, \bar{\theta}_{w}$ is the average measured volumetric water content, $\hat{\theta}_{w}$ is the estimated volumetric water content, $\mathrm{X}$ is the number of data points and $i$ is a counter. 
As shown in Figure 4, the coefficient of determination, $\mathrm{R}^{2}$, was computed to be 0.906 showing a good agreement between the measured and estimated SWCC data points. The reliability of the estimation procedure was investigated by computing the confidence interval of the observed error, $\left(\theta_{w i}-\hat{\theta}_{w i}\right)$, using a normal distribution in accordance with Equation 6.

$\mu\left(\theta_{w i}-\hat{\theta}_{w i}\right) \pm Z_{\alpha / 2} \sigma\left(\theta_{w i}-\hat{\theta}_{w i}\right)$

where $\mu=\frac{1}{X} \sum_{1}^{X} \theta_{w i}, \sigma=\sqrt{\frac{1}{X} \sum_{1}^{X}\left(\theta_{w i}-\mu\right)}, \alpha$ is the significance level.

The $95 \%$ confidence interval of the observed errors, $\left(\theta_{w i}-\hat{\theta}_{w i}\right)$, is shown in Figure 4 by dashed lines and it was found to be $(-0.046,0.083)$.

Figure 5 shows the GSD and the measured and estimated SWCC data point for two soils, 10839 and 11537, from the selected database presented in Table 1.

The soil numbers 10838 and 11537 are classified as clay and sandy loam according to USDA soil classification as indicated in SoilVision database. As shown in Figure 5b, the estimated SWCC data points had a good agreement with the measured SWCC data points for soil number 11537, while for soil 10839 the estimated SWCC data points underestimated the measured values (i.e., the estimated data points fell in the lower $95 \%$ confidence interval). The underestimated SWCC data points of the soil number 10839 could be due to the high clay content (i.e., clay $=47.83 \%$ ) as shown in Table 1 . It has been stated by Fredlund et al. (2002) that the main limitation associated with using the PTF methods is related to the increase of fines content of the soil. It should be noted that the effect of soil fabric is not considered in this study and further research is required on how to take into account its effect. 
The estimated SWCC data points in the high suction range can be used to complement the measured SWCC data up to the $100 \mathrm{kPa}$ suction value. The best-fit SWCC equation can be used to best-fit the completed SWCC data points including the measured and estimated ones by minimizing the residual sum of squares (SSE). The best-fitted SWCC can then be integrated to estimate the unsaturated permeability function. It should be noted that the estimated SWCC data points might contain error from the actual SWCC measurements. Therefore, only two data points beyond the suction value of $100 \mathrm{kPa}$ should be selected to complement the actual measured SWCC data points of soil up to a suction of $100 \mathrm{kPa}$. If more than two estimated SWCC data points in the high suction range are selected, these estimated points tend to influence the best-fitting procedure; as they could reduce the accuracy of the best-fit SWCC to the actual SWCC data below $100 \mathrm{kPa}$.

\section{Example soils from selected database to illustrate the application of the proposed procedure}

Four different best-fit SWCC equations of Fredlund and Xing (1994), Fredlund and Xing (1994) with $\mathrm{C}(\psi)=1$ as recommended by Leong and Rahardjo (1997a), van Genuchten (1980) and van Genuchten (1980) with $\mathrm{m}=1-1 / \mathrm{n}$ as described in details in Rahimi et al. (2015) were used to best-fit the: (a) the measured SWCC data up to a suction value of $100 \mathrm{kPa}$, (b) all the measured SWCC data points (i.e., available from the literature) and (c) combination of the measured SWCC data up to a suction value of $100 \mathrm{kPa}$ and estimated SWCC data points by the proposed procedure. Selected estimation models (i.e., FMM, VMM, FCM C $(\psi)=1$ and VCM $m=1-1 / n$ ) from the matrix of unsaturated permeability estimation models by Rahimi et al. (2015) were then used to estimate the unsaturated permeability functions of 11537 and 10838 soils and the results are shown in Figure 6 and Figure 7, respectively. 
As shown in Figure 6a, using only the measured SWCC data up to a suction value of $100 \mathrm{kPa}$ resulted in best-fit SWCCs varying from each other resulting in a large variation in unsaturated permeability functions as shown in Figure $6 \mathrm{~b}$. When all the measured SWCC data points were used in best-fitting exercise, the best-fitted SWCCs were close to each other (see Figure 6c) and consequently resulted in a smaller variation in unsaturated permeability functions (see Figure 6d). In addition, using the combination of measured SWCC data up to a suction value of $100 \mathrm{kPa}$ and estimated SWCC data points by the proposed procedure resulted in best-fit SWCCs that were close to each other (see Figure 6e) and consequently resulted in a smaller variation unsaturated permeability functions (see Figure 6f). Therefore, the estimated unsaturated permeability functions using the combination of measured SWCC data up to a suction value of $100 \mathrm{kPa}$ and estimated SWCC data points by the proposed procedure were more or less the same as the estimated unsaturated permeability functions using all the measured SWCC data points. This characteristic shows that the proposed procedure could reasonably reduce the variation between unsaturated permeability functions estimated by the different models. The same characteristic was observed for soil number 10838 as shown in Figure 7.

\section{Verification against direct measurement of unsaturated permeability}

SWCC and direct measurement of unsaturated permeability tests were performed on coarse kaolin, which was produced by Kaolin Malaysia SDN BHD (Malaysia). Soil specimens were prepared from reconstituted coarse kaolin to have homogeneous and uniform composition. The grain-size distribution of the coarse kaolin is shown in Figure 8.

The liquid and plastic limits of the coarse kaolin are 50.2\% and 30.3\%, respectively. The soil specimens for SWCC and permeability tests were prepared by static compaction (Ong 1999) 
at the maximum dry density $\left(\rho_{d \max }\right)$ of $1.4 \mathrm{Mg} / \mathrm{m}^{3}$ and optimum water content $\left(w_{\text {opt }}\right)$ of $23.9 \%$. The maximum dry density and optimum water content of the coarse kaolin were obtained from the standard Proctor compaction test (ASTM D698 1997). The coarse kaolin is classified as silt with high plasticity (MH) according to the unified soil classification system. The specimens were prepared at a diameter of $50 \mathrm{~mm}$ and height of $30 \mathrm{~mm}$. SWCC tests were performed using a Tempe pressure cell, 5-bar pressure plate, 15-bar pressure plate and saturated salt solutions in order to cover a wide suction range. A detailed explanation of all the test methods and procedures can be found in Rahimi (2015). A triaxial apparatus similar to the triaxial apparatus for unsaturated soil testing described by Fredlund and Rahardjo (1993) was used to conduct the unsaturated permeability tests. The design of the triaxial apparatus used in this study was based on the modifications done by Goh et al. (2014) and a detailed tests procedure can be found in Samingan et al. (2003).

Figure 9a shows the measured SWCC data up to a suction value of $100 \mathrm{kPa}$ and Figure 9c shows the full measured SWCC data. As shown in Figure 9a and 9b, the measured SWCC data were best-fit using the four SWCC equations described in Rahimi et al (2015). By comparing Figure 9a and Figure 9c, it can be seen that the best-fit SWCCs obtained using the full measurement of SWCC data were similar over the entire suction range while the best-fit SWCCs obtained using only the measured data up to the suction value of $100 \mathrm{kPa}$ had the same shape until a suction value of $100 \mathrm{kPa}$, beyond which they started to vary significantly. This is similar to the conclusion obtained for the soils from the database.

The estimated unsaturated permeability curves by FMM, VMM, FCM C $(\psi)=1$ and VCM $\mathrm{m}=1-1 / \mathrm{n}$ estimation models (Rahimi et al. 2015) using the best-fit SWCCs for SWCC data up to $100 \mathrm{kPa}$ along with the directly measured unsaturated permeability data of coarse kaolin are shown in Figure 9b. The estimated unsaturated permeability curves by FMM, VMM, 
FCM $C(\psi)=1$ and VCM m=1-1/n estimation models (Rahimi et al. 2015) using the best-fit SWCCs for the full measurement of SWCC data along with the directly measured unsaturated permeability data of coarse kaolin are shown in Figure 9d. By comparing Figure $9 \mathrm{~b}$ and, Figure 9d, it can be seen that the variation between the estimated unsaturated permeability curves was quite small when the best-fit SWCCs using the full measurement of SWCC data were used as compared to that when only the best-fit SWCCs using measured SWCC data up to $100 \mathrm{kPa}$ were used.

Figure 9e shows the results of the best-fit SWCCs for the coarse kaolin using the measured SWCC data up to $100 \mathrm{kPa}$ in combination with the estimated SWCC data points using the proposed procedure. The four best-fit SWCCs were quite close to each other as shown in Figure 9e as compared to that shown in Figure 9a, which only used the measured SWCC data up to $100 \mathrm{kPa}$. The estimated unsaturated permeability curves for the coarse kaolin using the best-fit SWCCs by the measured SWCC data up to $100 \mathrm{kPa}$ in combination with the estimated SWCC data points are shown in Figure 9f. It can be seen from the figure that the variation between the estimated unsaturated permeability curves was significantly lower than that shown in Figure 9b, where only the measured SWCC data up to $100 \mathrm{kPa}$ was used.

\section{Conclusions}

The estimated SWCC at a higher suction by the proposed procedure (using the grain size distribution and SWCC measured data of up to $100 \mathrm{kPa}$ ) successfully eliminated the variation in best-fit SWCCs and estimated unsaturated permeabilities due to the limited measured SWCC data. The proposed method also provided a good fit to the directly measured unsaturated permeability data. Therefore, this method can be used to eliminate the need for SWCC measurement over a wide suction range. This approach can provide a reliable 
estimation of unsaturated permeability in a reasonable amount of time with inexpensive equipment.

\section{References}

Ahuja, L., Naney, J., and Williams, R. D. 1985. Estimating soil water characteristics from simpler properties or limited data. Soil Science Society of America Journal, 49(5): 1100-1105.

Arya, L. M., and Paris, J. F. 1981. A Physicoempirical Model To Predict The Soil Moisture Characteristic From Particle-size Distribution And Bulk Density Data. Soil Science Society of America Journal, 45(6): 1023-1030.

ASTM 1997. Test Method for Laboratory Compaction Characteristic of Soil Using Standard Effort. Annual Books of ASTM Standard D698, 4.8(4): 77-87 West Conshohocken, Philadenphia.

Bouma, J. 1989. Using soil survey data for quantitative land evaluation. In: Advance in soil science, B.A. Stewart (ed.). Springer-Verlag New York. Vol. 9 (1989) 225-239.

Chin, K. B., Leong, E. C., and Rahardjo, H. 2010. A simplified method to estimate the soilwater characteristic curve. Canadian Geotechnical Journal, 47(12): 1382-1400.

Fredlund, M. D., Wilson, G. W., and Fredlund, D. G. 2002. Use of the grain sizedistribution for estimation of the soil-water characteristic curve. Canadian Geotechnical Journal, 39(5): 1103-1117.

Fredlund, D. G. and Xing, A. 1994. Equations for the soil-water characteristic curve. Canadian Geotechnical Journal, 31(4): 521-532. 
Fredlund, D. G. and Rahardjo, H. 1993. Soil mechanics for unsaturated soils. New York : Wiley, 1993.

Goh, S. G., Rahardjo, H., and Leong, E.C. 2015. Modification of triaxial apparatus for permeability measurement of unsaturated soils. Soils and Foundations, "In Press"

Garg, A., Garg, A., Tai, K., Barontini, S., and Stokes, A. 2014. A Computational Intelligence-Based Genetic Programming Approach for the Simulation of Soil Water Retention Curves. Transport in Porous Media, 103(3): 497-513.

Gupta, S. C., and Larson, W. E. 1979. Estimating soil water retention characteristics from particle size distribution, organic matter percent, and bulk density. Water Resources Research, 15(6): 1633-1635.

Jaafar, R. and Likos, W. J. 2011. Estimating water retention characteristics of sands from grain size distribution using idealized packing conditions. Geotechnical Testing Journal 34(5).

Johari, A., Habibagahi, G., and Ghahremani, A. 2006. Prediction of soil-water characteristic curve using genetic programming. Journal of Geotechnical and Geoenvironmental Engineering, 132(5): 661-665.

Kovács, G. 1981. Seepage hydraulics / by György Kovács ; [translated by Katalin Kovács], Amsterdam ; New York : Elsevier Scientific Pub. Co.: distribution for the U.S.A. and Canada, Elsevier/North-Holland, 1981.

Kunze, R. J., Uehara, G., and Graham, K. 1968. Factors important in the calculation of hydraulic conductivity. Soil Science Society of America Journal, 32(6): 760-765. 
Leong, E. C. and Rahardjo, H. 1997. Review of soil-water characteristic curve equations. Journal of Geotechnical and Geoenvironmental Engineering, 123(12): 1106-1117.

Ong, B. H. 1999. Shear Strength and Volume Change of Unsaturated Soil. Master of Engineering Thesis, Nanyang Technological University, Singapore.

Pachepsky, Y. A., Timlin, D., and Varallyay, G. Y. 1996. Artificial neural networks to estimate soil water retention from easily measurable data. Soil Science Society of America Journal, 60(3): 727-733.

Rahardjo, H., Satyanaga, A., D'Amorec, G.A.R., and Leong, E.C. 2012. Soil-water characteristic curves of gap-graded soils. Engineering Geology, 125(27): 102-107.

Rahimi, A. 2015. Parameters affecting estimation of unsaturated permeability of soils. $\mathrm{PhD}$ thesis, Nanyang Technological University, Singapore.

Rahimi, A., Rahardjo, H., and Leong, E.C. 2015. Effect of range of soil-water characteristic curve measurements on estimation of permeability function. Engineering Geology, 185: 96-104.

Rahimi, A., Rahardjo, H., and Leong, E.C. 2014. Underlying parameters affecting estimation of unsaturated permeability of soils. In Proceedings of the Unsaturated Soils: Research \& Applications, Sydney, July 2014. pp. 1073-1077.

Samingan, A. S., Leong, E. C. and Rahardjo, H. 2003. A flexible wall permeameter for measurements of water and air coefficients of permeability of residual soils. Canadian Geotechnical Journal, 40(3): 559-574. 
Saxton, K., Rawls, W. J., Romberger, J. S., and Papendick, R. I. 1986. Estimating generalized soil-water characteristics from texture. Soil Science Society of America Journal, 50(4): 1031-1036.

Sillers, W. S., Fredlund, D. G., and Zakerzadeh, N. 2001. Mathematical attributes of some soil-water characteristic curve models. Geotechnical and Geological Engineering 19(3-4): 243-283.

Smettem, K., and Gregory, P. 1996. The relation between soil water retention and particle size distribution parameters for some predominantly sandy Western Australian soils. Soil Research, 34(5): 695-708.

SoilVision Systems Ltd. 2006. SoilVision: a knowledge based database system for unsaturated-saturated soil properties (computer programme), version 4.0. SoilVision Systems Ltd., Saskatoon, Canada.

van Genuchten, M. T. 1980. Closed-form equation for predicting the hydraulic conductivity of unsaturated soils. Soil Science Society of America Journal, 44(5): 892-898.

Wösten, J., Pachepsky, Y. A., and Rawls, W. J. 2001. Pedotransfer functions: bridging the gap between available basic soil data and missing soil hydraulic characteristics. Journal of hydrology, 251(3): 123-150.

Zapata, C. E. 1999. Uncertainty in soil-water-characteristic curve and impacts on unsaturated shear strength predictions, Arizona State University. 


\section{Tables}

Table 1-Selected soil database for evaluation of the proposed estimation procedure of SWCC data points in a high suction range

\begin{tabular}{|c|c|c|c|c|c|c|c|c|}
\hline & $\begin{array}{c}\text { Soil } \\
\text { counter }\end{array}$ & $\begin{array}{l}\text { Minimum } \\
\text { diameter } \\
(\mathbf{m m})\end{array}$ & $\begin{array}{c}\text { PF of } \\
\text { minimum } \\
\text { diameter } \\
(\%)\end{array}$ & $\begin{array}{c}\text { Maximum } \\
\text { measured } \\
\text { suction } \\
(\mathbf{k P a})\end{array}$ & $\begin{array}{c}\text { Maximum } \\
\text { estimated } \\
\text { suction } \\
(\mathbf{k P a})\end{array}$ & $\begin{array}{l}\text { Clay } \\
(\%)\end{array}$ & $\begin{array}{l}\text { Silt } \\
(\%)\end{array}$ & $\begin{array}{c}\text { Sand } \\
(\%)\end{array}$ \\
\hline 1 & 262 & 0.0028 & 0.120 & 513291.9 & 619.1 & 16.71 & 78.75 & 4.74 \\
\hline 2 & 1446 & 0.002 & 0.520 & 1500.93 & 400.248 & 57.47 & 35.72 & 6.81 \\
\hline 3 & 10760 & 0.002 & 0.318 & 981 & 981 & 42.23 & 25.4 & 32.243 \\
\hline 4 & 10762 & 0.002 & 0.075 & 1500.93 & 500.31 & 12.55 & 21.05 & 66.18 \\
\hline 5 & 10763 & 0.002 & 0.215 & 1500.93 & 500 & 25.75 & 18.79 & 55.37 \\
\hline 6 & 10765 & 0.002 & 0.405 & 1500.93 & 500.31 & 41.55 & 13.79 & 44.65 \\
\hline 7 & 10774 & 0.002 & 0.080 & 1471.5 & 392.4 & 11.61 & 11.19 & 77.05 \\
\hline 8 & 10776 & 0.002 & 0.490 & 1471.5 & 392.4 & 53.94 & 9.32 & 36.29 \\
\hline 9 & 10777 & 0.002 & 0.470 & 1471.5 & 392.4 & 50.1 & 10.36 & 39.36 \\
\hline 10 & 10831 & 0.002 & 0.470 & 1471.5 & 294.3 & 66.54 & 29.53 & 3.89 \\
\hline 11 & 10836 & 0.002 & 0.170 & 1554.885 & 619.011 & 20.35 & 66.33 & 13.32 \\
\hline 12 & 10838 & 0.002 & 0.435 & 1554.885 & 619.011 & 66.54 & 29.53 & 3.89 \\
\hline 13 & 10839 & 0.002 & 0.403 & 1554.885 & 619.011 & 47.83 & 42.5 & 9.66 \\
\hline 14 & 10843 & 0.002 & 0.351 & 1554.885 & 619.011 & 41.37 & 52.32 & 6.3 \\
\hline 15 & 10847 & 0.002 & 0.407 & 1554.885 & 619.011 & 57.46 & 38.21 & 4.3 \\
\hline 16 & 10851 & 0.002 & 0.581 & 1554.885 & 619.011 & 70.97 & 28.32 & 0.71 \\
\hline 17 & 10862 & 0.002 & 0.219 & 1554.885 & 619.011 & 25.37 & 64.93 & 9.7 \\
\hline 18 & 10980 & 0.002 & 0.450 & 1471.5 & 784.8 & 52.6 & 32.29 & 14.84 \\
\hline 19 & 10981 & 0.002 & 0.570 & 1471.5 & 784.8 & 69.35 & 27.92 & 2.72 \\
\hline 20 & 10982 & 0.002 & 0.630 & 1471.5 & 784.8 & 76.74 & 20.52 & 2.68 \\
\hline 21 & 11037 & 0.002 & 0.380 & 1471.5 & 294.3 & 47.62 & 51.28 & 1.1 \\
\hline 22 & 11159 & 0.002 & 0.435 & 1500.93 & 500.31 & 62.37 & 34.89 & 2.73 \\
\hline 23 & 11219 & 0.002 & 0.200 & 1013.373 & 567.509 & 30.04 & 69.78 & 0.17 \\
\hline 24 & 11222 & 0.002 & 0.290 & 961.7724 & 961.772 & 34.62 & 65.35 & 0.03 \\
\hline 25 & 11224 & 0.002 & 0.205 & 961.7724 & 961.772 & 43.79 & 56.21 & 0 \\
\hline 26 & 11261 & 0.002 & 0.151 & 1471.5 & 618.03 & 19.03 & 80.3 & 0.67 \\
\hline 27 & 11267 & 0.0014 & 0.137 & 163.827 & 163.827 & 18.59 & 79.51 & 1.9 \\
\hline 28 & 11271 & 0.002 & 0.181 & 931.95 & 931.95 & 23.67 & 75.16 & 1.17 \\
\hline 29 & 11405 & 0.002 & 0.070 & 1471.5 & 981 & 11.27 & 87.56 & 1.17 \\
\hline 30 & 11409 & 0.002 & 0.473 & 1471.5 & 981 & 54.93 & 37 & 8.05 \\
\hline 31 & 11410 & 0.002 & 0.544 & 1471.5 & 981 & 62.51 & 29.62 & 7.77 \\
\hline 32 & 11474 & 0.0014 & 0.137 & 1471.5 & 1471.5 & 14.83 & 6.93 & 78.18 \\
\hline 33 & 11477 & 0.002 & 0.011 & 1471.5 & 490.5 & 1.16 & 3.16 & 95.68 \\
\hline 34 & 11496 & 0.0014 & 0.111 & 500 & 500 & 16.49 & 16.94 & 65.76 \\
\hline 35 & 11497 & 0.0014 & 0.137 & 300 & 300 & 14.83 & 6.93 & 78.18 \\
\hline 36 & 11525 & 0.0014 & 0.142 & 300 & 300 & 19 & 10.97 & 69.68 \\
\hline 37 & 11537 & 0.0014 & 0.115 & 500 & 500 & 15.62 & 19.58 & 64.51 \\
\hline 38 & 11540 & 0.0014 & 0.225 & 400 & 400 & 34.69 & 37.68 & 26.88 \\
\hline 39 & 12217 & 0.001 & 0.397 & 324.319 & 324.319 & 52.58 & 46.6 & 0.82 \\
\hline 40 & 18748 & 0.002 & 0.250 & 1000000 & 870.9634 & 32.76 & 22.46 & 43.45 \\
\hline
\end{tabular}




\section{List of Figures}

Figure 1-Grain-size distribution of a typical soil

Figure 2-Idealized dense packing condition of soil grains

Figure 3-A schematic diagram for the proposed estimation method

Figure 4-Estimated versus measured water content for selected soil database with $95 \%$ confidence intervals

Figure 5-Grain-size distribution and measured and estimated SWCC data points for soil numbers 10839 and 11537

Figure 6-SWCC and estimated unsaturated permeability function of soil number 11537

Figure 7-SWCC and estimated unsaturated permeability function of soil number 10838

Figure 8-Grain-size distribution curve of coarse kaolin

Figure 9-SWCC and estimated unsaturated permeability function of coarse kaolin 


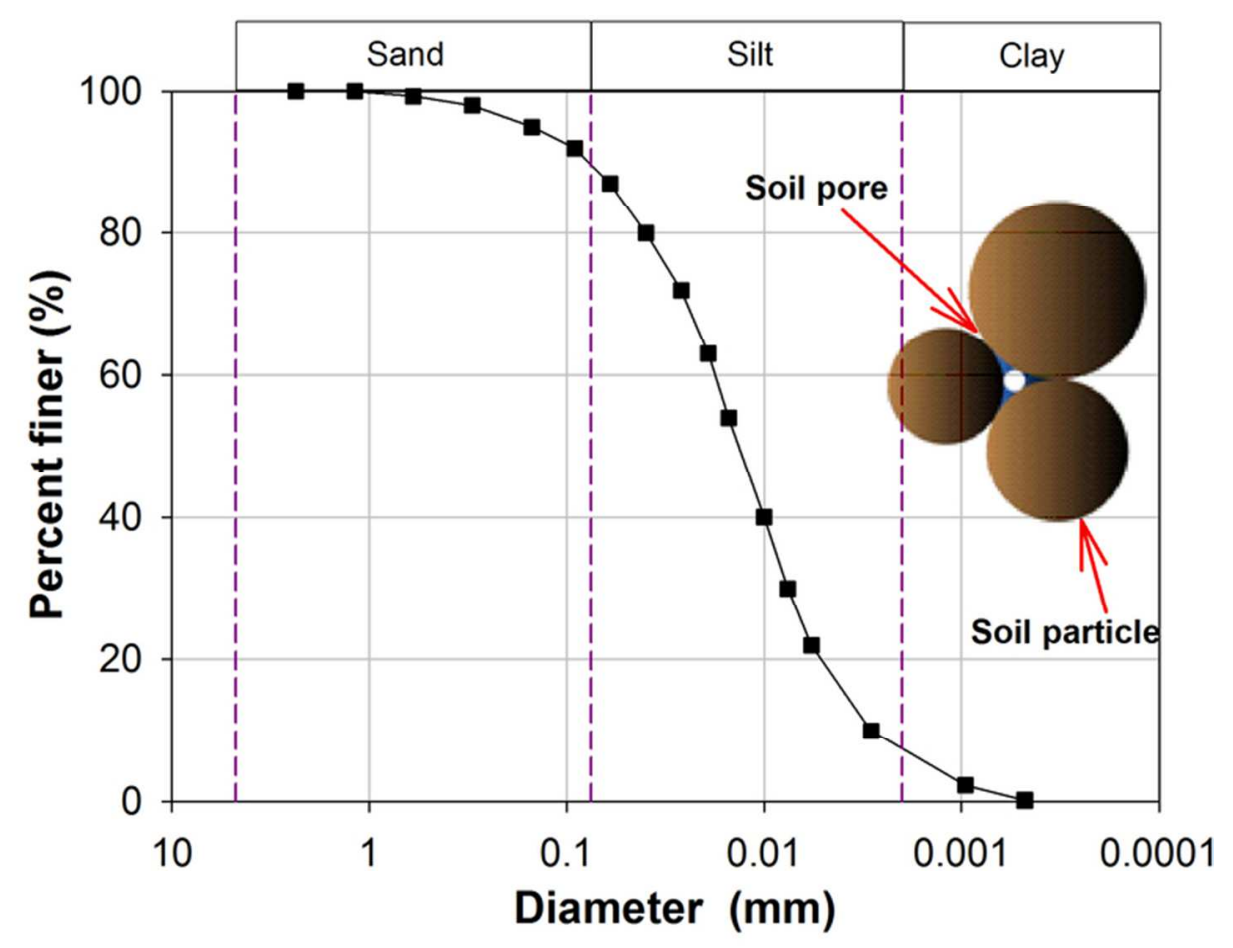

Figure 1-Grain-size distribution of a typical soil $70 \times 57 \mathrm{~mm}$ (300 x 300 DPI) 


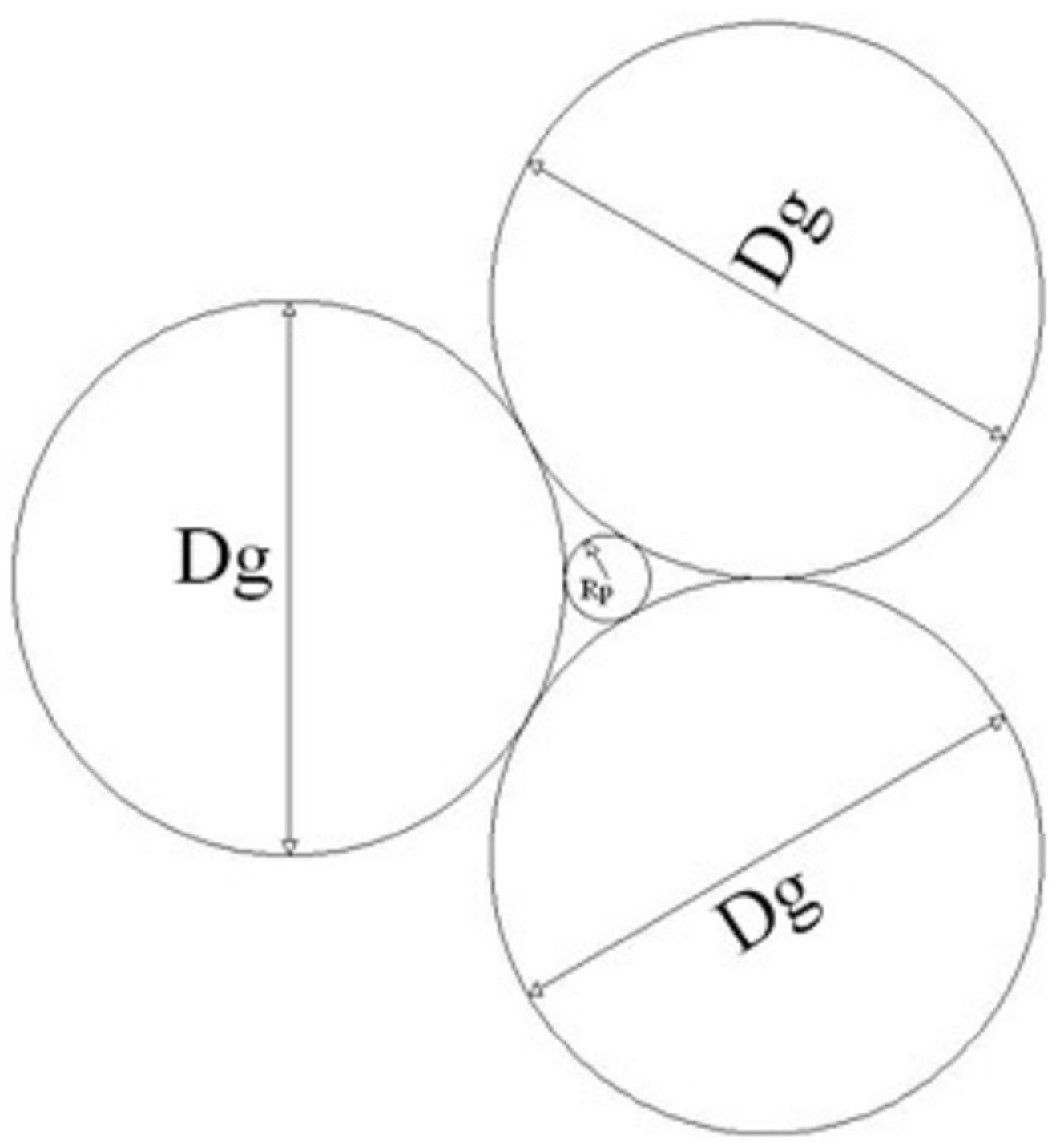

Figure 2-Idealized dense packing condition of soil grains $242 \times 261 \mathrm{~mm}(96 \times 96 \mathrm{DPI})$ 
1- Find $\mathrm{D}_{(100)}$ using:
\[ \psi D_{(100)}=(12+8 \sqrt{3}) \frac{T_{s}}{\rho_{w} g D_{(100)}} \]

2- Find PF of $D_{(100)}$ from GSD curve

3- Compute water content at $\mathrm{D}_{(100)}$ using:

$$
W C_{D_{(100)}}=\frac{P F_{D_{(100)}} \times W C_{S a t}}{100}
$$

4- Compute scaled factor using:

$$
S_{f}=\frac{W C_{(100)}}{W C_{m}}
$$

5- Compute equevalent suctions of grain sizes smaller than $\mathrm{D}_{(100)}$ using:

$$
\psi D_{(X n)}=(12+8 \sqrt{3}) \frac{T_{s}}{\rho_{w} g D_{(X n)}}
$$

6- Compute and scale water contents at respective computed suctions using:

$$
W C_{D_{(X n)}}=\frac{P F_{D_{(X n)}} \times W C S a t}{S_{f}}
$$

Figure 3-A schematic diagram for the proposed estimation method $87 \times 144 \mathrm{~mm}(96 \times 96$ DPI) 


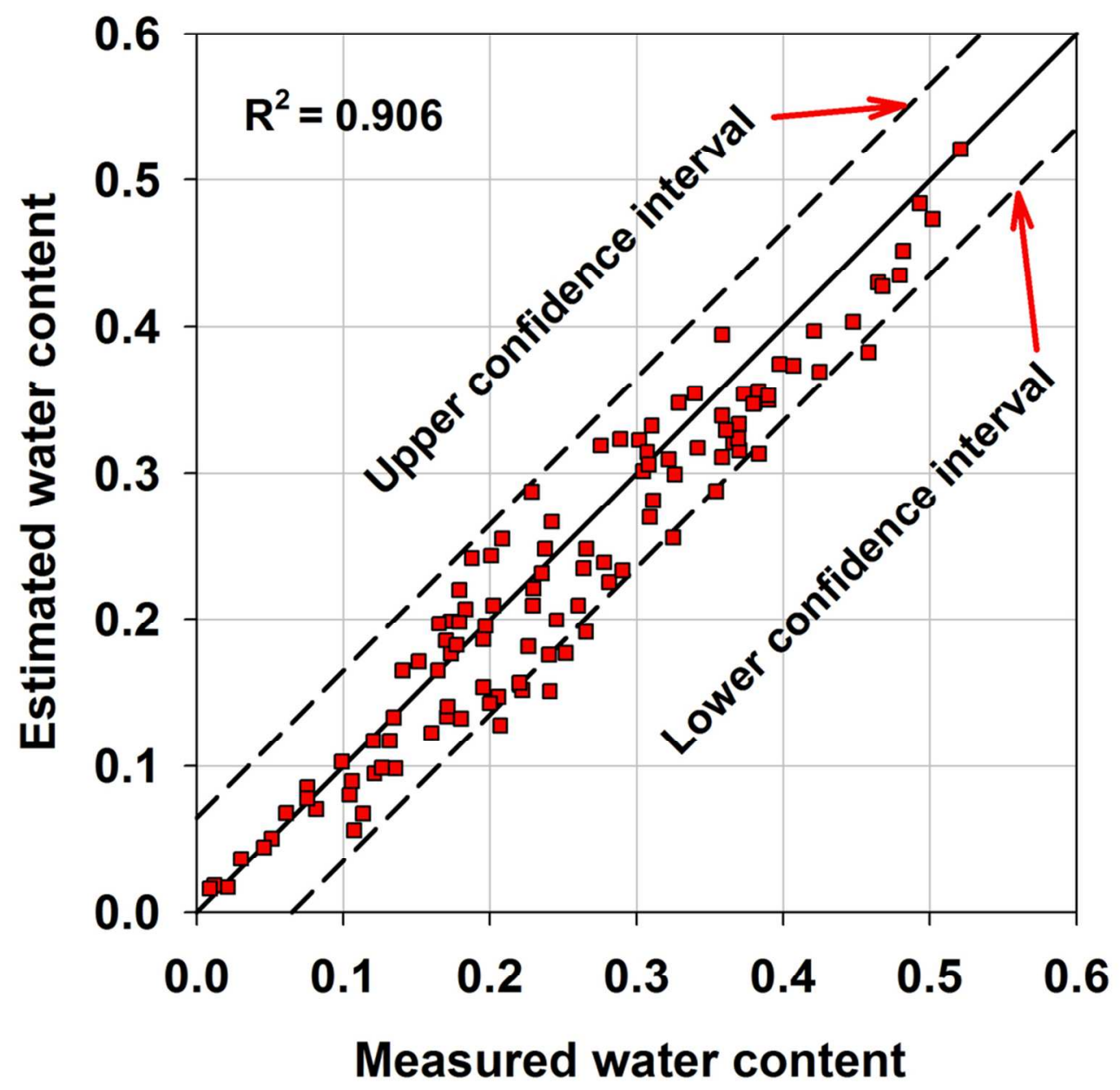

Figure 4-Estimated versus measured water content for selected soil database with $95 \%$ confidence intervals $89 \times 92 \mathrm{~mm}(300 \times 300$ DPI $)$ 

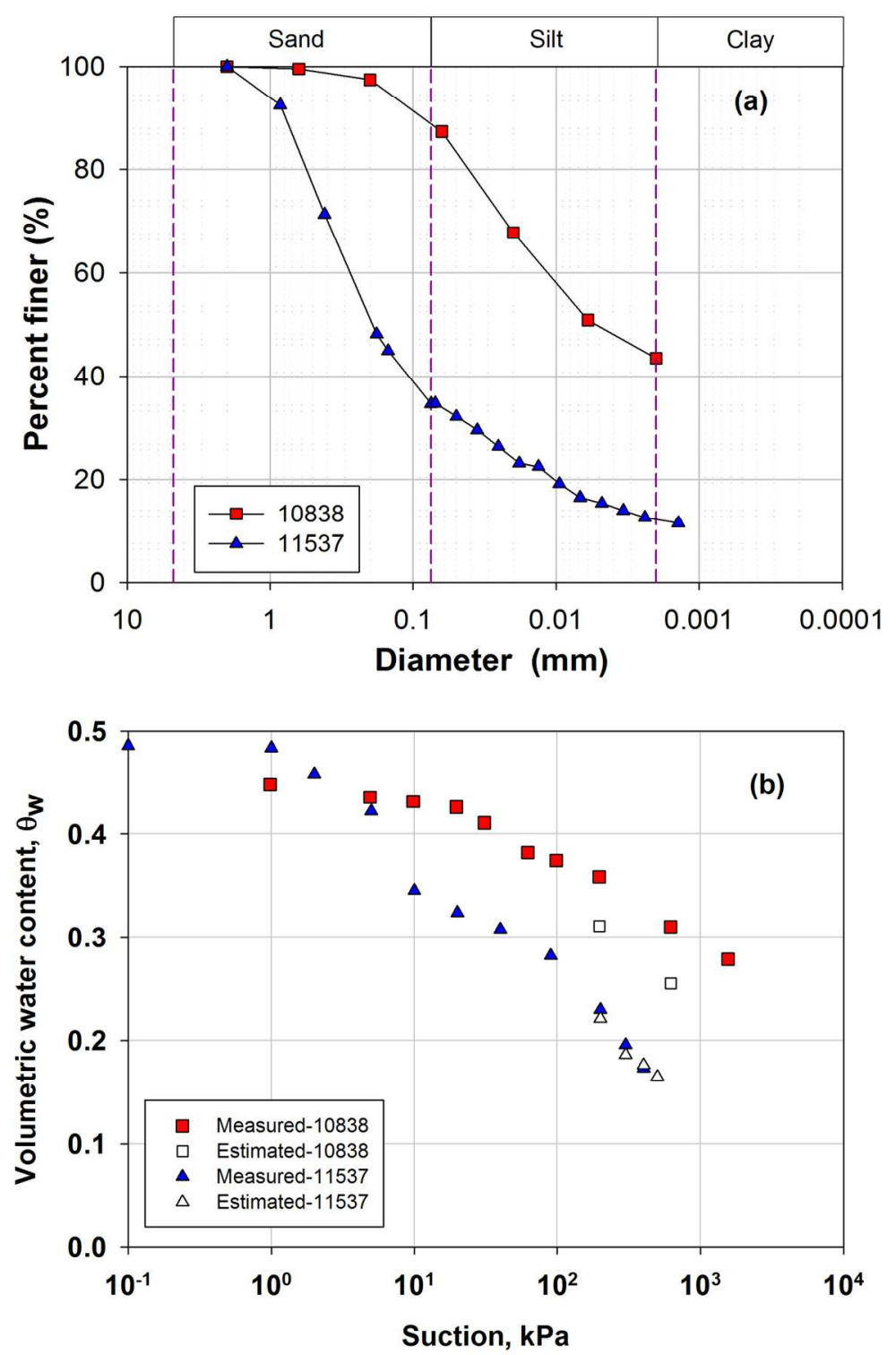

Figure 5-Grain-size distribution and measured and estimated SWCC data points for soil numbers 10839 and 11537

$126 \times 186 \mathrm{~mm}(300 \times 300$ DPI $)$ 

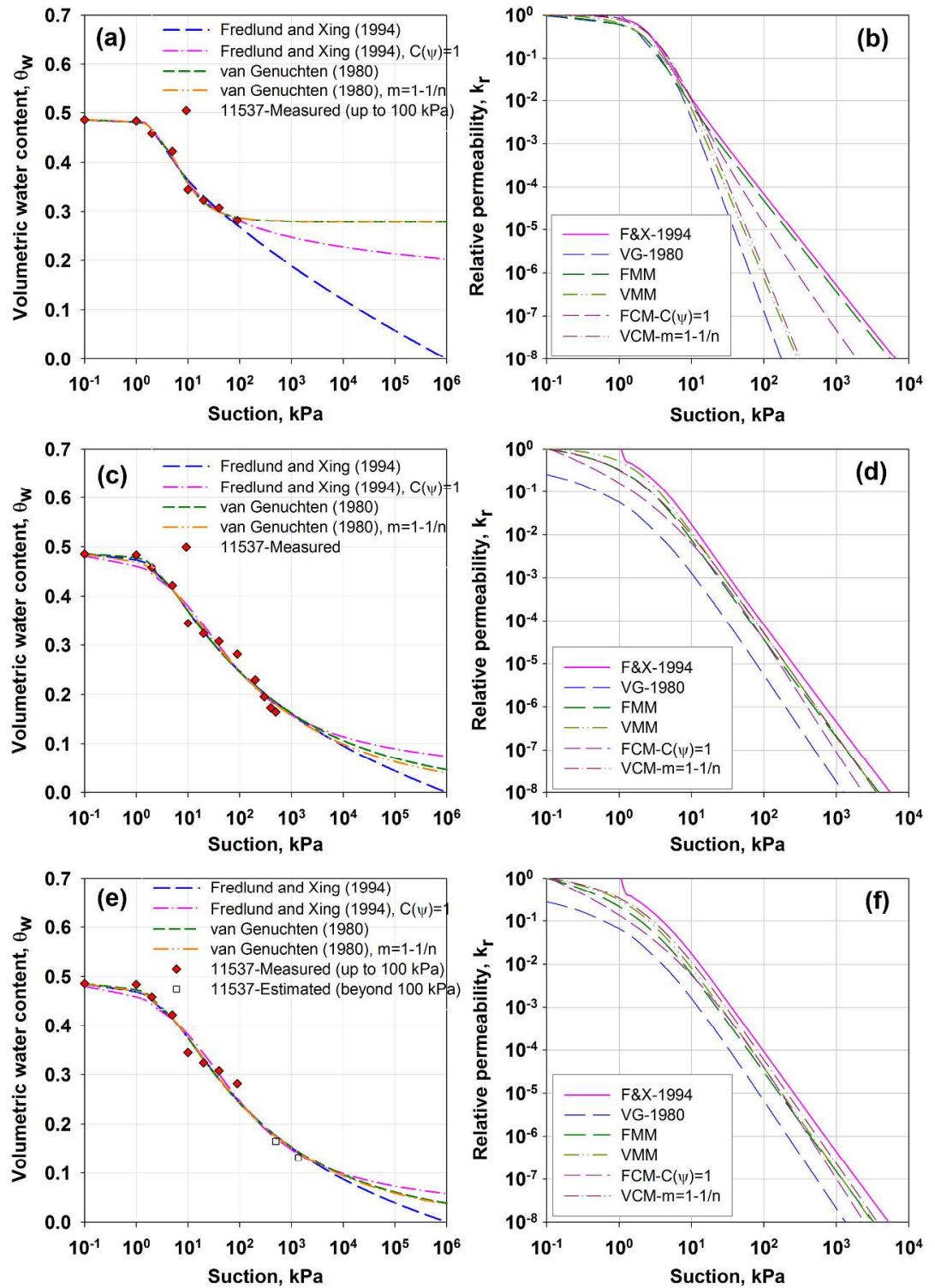

Figure 6-SWCC and estimated unsaturated permeability function of soil number 11537 $259 \times 369 \mathrm{~mm}(300 \times 300 \mathrm{DPI})$ 

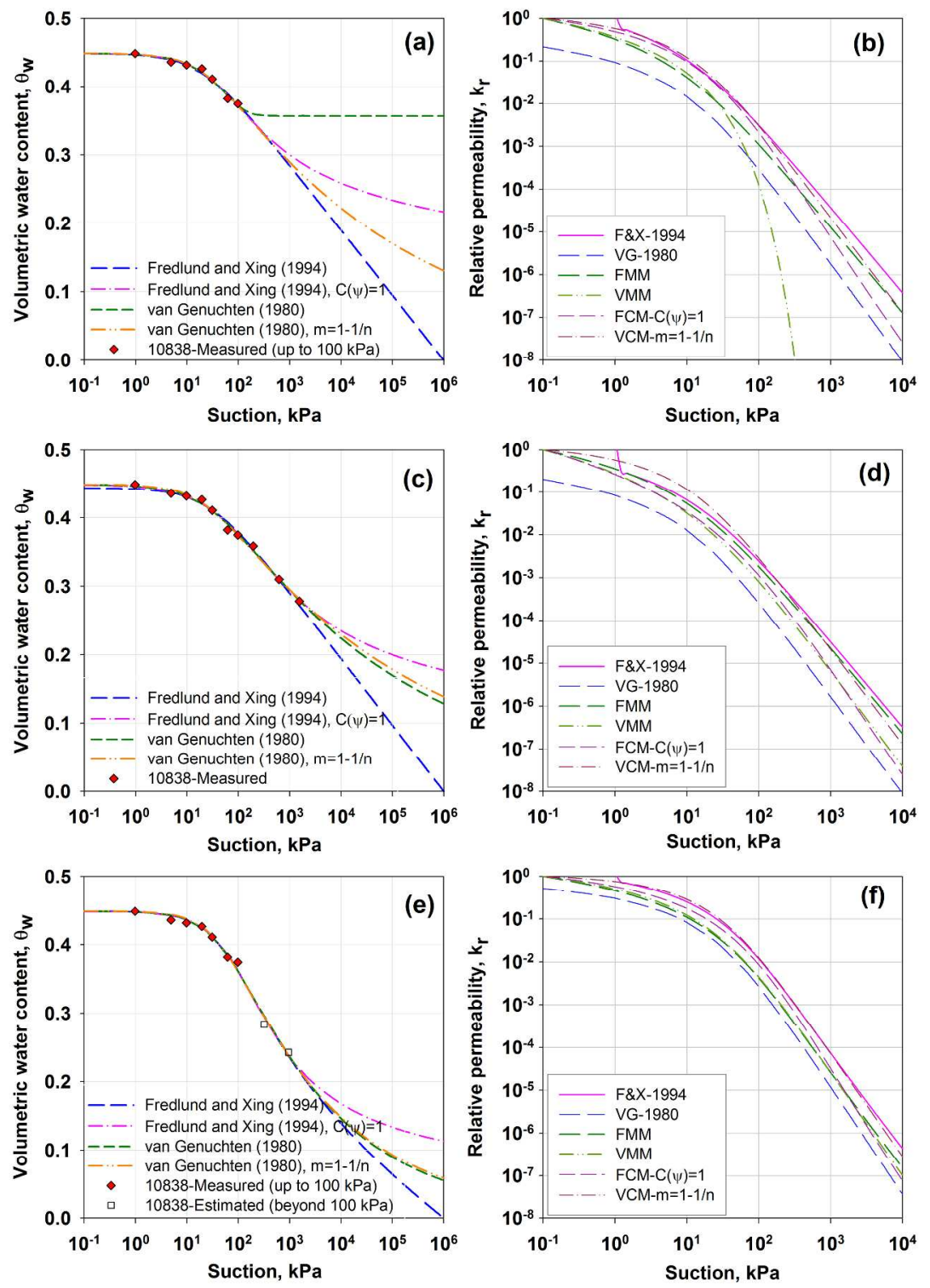

Figure 7-SWCC and estimated unsaturated permeability function of soil number 10838 $259 \times 371 \mathrm{~mm}(300 \times 300 \mathrm{DPI})$ 


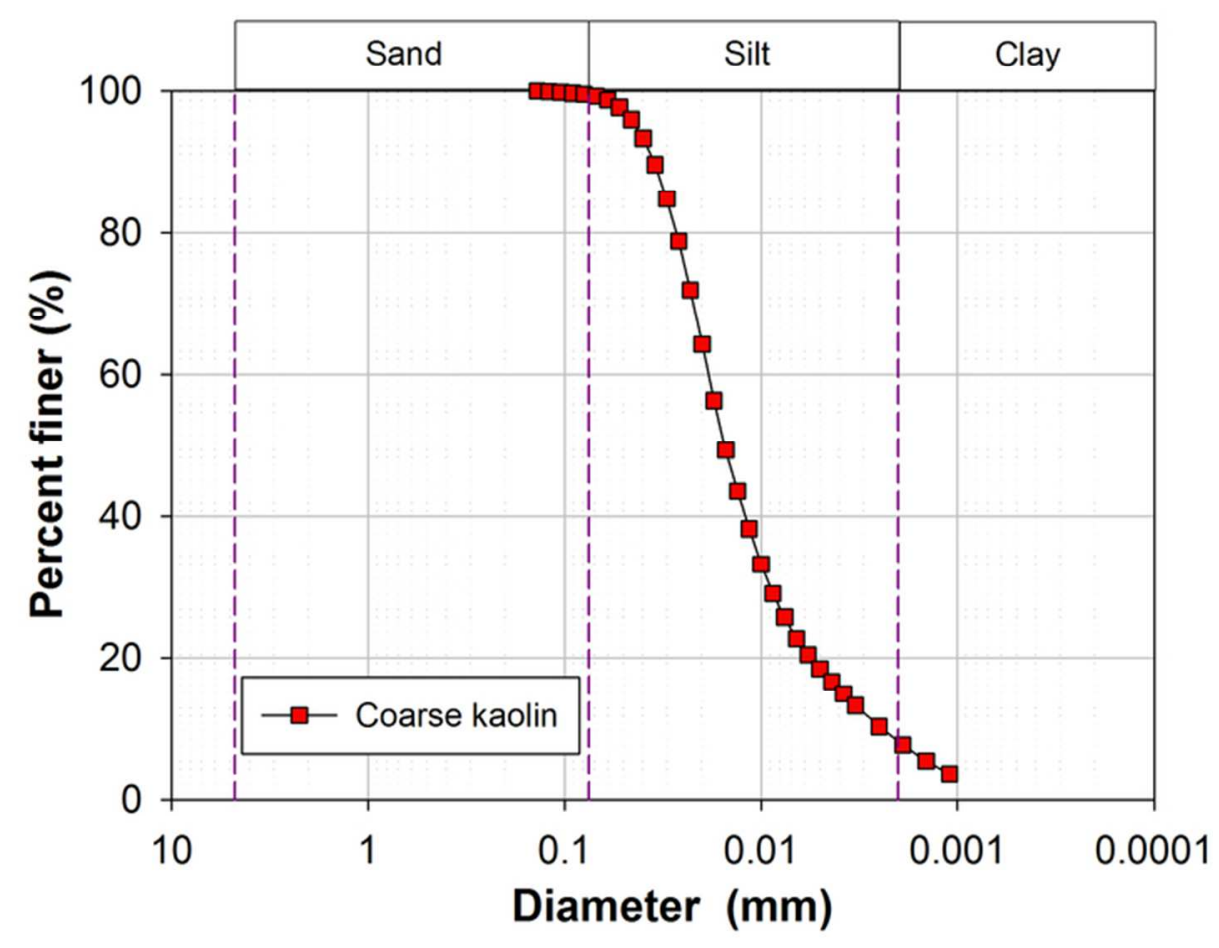

Figure 8-Grain-size distribution curve of coarse kaolin $65 \times 50 \mathrm{~mm}(300 \times 300 \mathrm{DPI})$ 

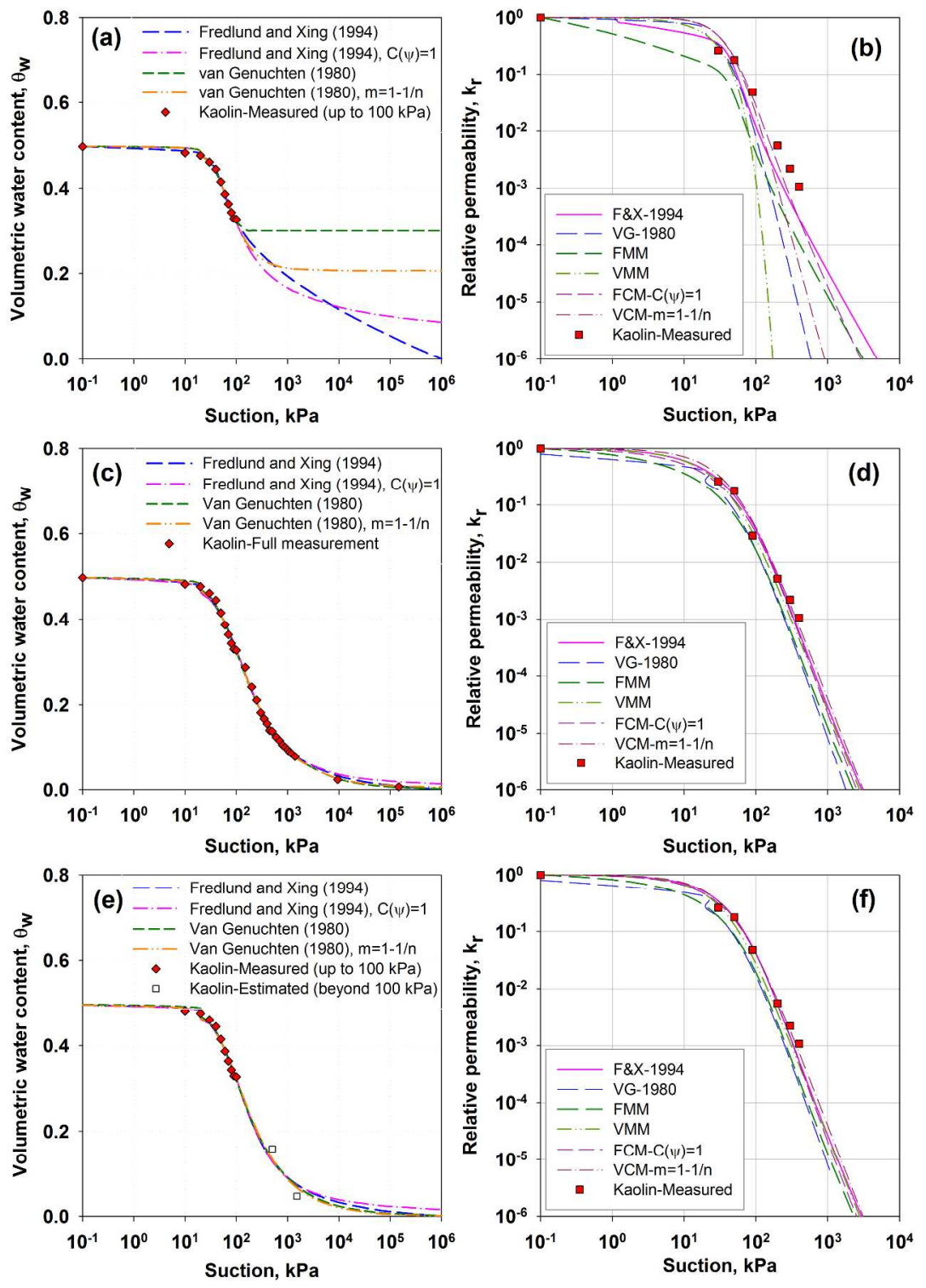

Figure 9-SWCC and estimated unsaturated permeability function of coarse kaolin $259 \times 369 \mathrm{~mm}(300 \times 300$ DPI) 